\title{
Effect of Shared Governance Educational Program on knowledge, perceptions and Autonomy of
} Professional Nurses

\author{
Abeer Abdallah Ali ${ }^{1}$, Mahasen Ismail Abdelmegeed ${ }^{2}$, Sahar Ahmed Abood ${ }^{3}$
}

${ }^{1}$ (M.Sc, Nursing Administration, Faculty of Nursing, Minia University, Egypt)

${ }^{2}$ (Professor of Nursing Administration, Faculty of Nursing, Cairo University, Egypt)

3 (Professor of Nursing Administration, Faculty of Nursing, Minia University, Egypt)

\begin{abstract}
Background: Shared governance is a model in which staff collaborate through a decentralized decision making structure, sharing ownership and accountability and partnering to make decisions about clinical practice, professional development, patient safety and quality improvement. Aim: of this study was to investigate the effect of shared governance educational program on knowledge, perceptions and autonomy of professional nurses. Design: A quasiexperimental research was utilized. Setting: The study was carried out in five of Minia University Hospitals including the Main University Hospital; Gynecology, Obstetrics and Pediatrics Hospital; Cardio-Thoracic Hospital; Renal and Urology Hospital in addition to the Dental Hospital. Subjects: Participants of the study were a probability sample of professional nurses $(\mathrm{no}=78)$ drained from the total baccalaureate-prepared nurses who were working in the previously mentioned Hospitals at the study conduction period. Tools: Two tools were used; Nurses Knowledge and Perceptions of Shared Governance Questionnaire, and Professional Nursing Autonomy Scale. Results: There was a high statistically significant improvement in the level of nurses' knowledge and perceptions of shared governance as well as in their level of perceived professional autonomy from its three perspectives at all test measures that followed implementing the educational program than what was before program implementation. Conclusion: The educational intervention carried out within the context of this study was successful at improving the knowledge, perceptions and autonomy of professional nurses. Recommendations: This study especially emphasize that continuing education is a consolidated way to ensure the implementation of shared governance and promotes professional nursing autonomy.

Keywords: Shared Governance, Knowledge, Perceptions, Professional Autonomy, Nurses.
\end{abstract}

\section{Introduction}

Governance is a topic that should be explored in the management research field in general and nursing and health management specifically. It can help increase nurses' autonomy and scope of responsibilities. In the health care area, the use of the term governance has been growing, especially in the context of discussions about good management practices that could be adopted to improve care delivery for individuals and population. A principle of governance is the participation and involvement of professionals in management and decision making process at organizations and health services, these professionals should be as committed as his/her managers with results of care to be achieved (Santos et al., 2013).

The changing context of society and healthcare called for a restructuring of hospital administration that emphasized collaboration, a defined knowledge base, autonomous practice, and shared decision making. Moreover, nurses are the closest to patients and the point of care. They hold scientific knowledge upon which to provide care across the continuum of healthcare services. Furthermore, nurses have the unique ability to partner with other health care professional in redesigning the healthcare system (Charland, 2015).

In the context of nursing, professional governance corresponds to the processes and structures that provide autonomy, control and authority to nurses regarding the nursing practices within an organization (Barden et al., 2012). The first governance model for nursing was designed in the 1980s, in the United States, and called "shared governance" (Hess \& Swihart, 2013; Santos et al., 2013). The model is based on the assumption that nurses, as the main frontline health workers, are more qualified to assess and decide which are the care needs of patients, based on

$P$ a g e | 198 parameters of clinical practice guidelines (Barden et al., 2012; Hess \& Swihart, 2013).

Shared governance is seen as a strategy to build a partnership, create ownership, and facilitate equity and accountability between the nurses and the work environment (Al-Faouri et al., 2014). As a management innovation, shared governance implementation was a strategy to enhance professional nursing practice to transform the organization from a bureaucratic, hierarchy to a more organic, relational partnership (Charland, 2015).

Autonomy has been described as having the authority to make independent decisions and to take actions in accordance with one's discretion and professional knowledge. To function autonomously, however, nurses must develop the expertise that allows them to exercise sound clinical judgment and exert control over their practice. Certain satisfiers must be met, for example, resources must be provided and autonomy supported to achieve an adequate level of competency (Shepherd et al., 2014).

\section{Significance of the Study}

During supervising the rotations of clinical training for nursing students at Minia University Hospitals, the researcher noted different situations showing the number of assessments, decision-making, independent procedures, and interactions that a professional nurse might undertake within a single work shift, however, the authority given to nurses for independent judgment seems much more limited either by organizational constraints, legal/professional practice parameters, absence of specified job descriptions of nursing categories, or by the individual nurse's own confidence and perception of competence.

In addition, it was noted also by the researcher that shared governance studies started to appear in the Egyptian nursing research. Despite, most of these studies were

\section{(1)}


descriptive in nature mainly focusing on assessing the perceptions of shared governance and its relation to nurses empowerment, job satisfaction or organizational commitment, however, the present study was the first one to be carried out that involve monitoring the professional nurses' knowledge and perceptions of shared governance before and after implementing an educational program and to spotlights whether this educational intervention would affect their level of perceived autonomy.

\section{Aim of the study:}

The aim of this study was to investigate the effect of shared governance educational program on knowledge, perceptions and autonomy of professional nurses.

\section{Research Hypothesis:}

1) Professional nurses' knowledge and perceptions of shared governance will be higher after the educational program than before.

2) Professional nurses' level of autonomy will be different before and after the educational program.

3) There will be a relationship between professional nurses' knowledge and perceptions of shared governance and their level of autonomy before and after the educational program.

\section{Subjects and methods}

\section{Research design:}

Quasi-experimental design was utilized in this study.

\section{Setting:}

The study was conducted in five of Minia University Hospitals including: (The Main University Hospital, Cardiothoracic Hospital, Gynecology, Obstetrics and Pediatrics Hospital, Renal and Urology Hospital in addition to the Dental Hospital).

\section{Subjects}

The study sample included (78) nurse drained by the probability sampling technique from the total no (100) of baccalaureate prepared nurses working at the previously mentioned hospitals during the time of conducting the study.

\section{Tools of data collection:}

Two tools were used to collect the research data for this study as follows: -

Tool 1: Nurses Knowledge and Perceptions of Shared Governance Questionnaire. It was consisted of three parts:

Part I: included the socio-demographic characteristics of the study sample as (age, gender, place of residence, current job position, years of experience and work department).

Part II: included 20 items developed by the researcher based on the literature review to identify nurses' knowledge of shared governance with 2 responses (1) I don't know and (2) Yes I know. Total score of knowledge (> 60\%) considered "satisfactory "level and otherwise considered "unsatisfactory "level.

Part III: included 18-items adapted by the researcher from (Rundquist, 2014) to measure nurses' perceptions of shared governance on 3-point Likert scale ranged from (1) disagree,
(2) neutral and (3) agree. The score was reversed for negative items. Total scores of (18-30) indicate "low", while scores (31- 42) considered "moderate "and scores (43-54) considered "high "level of perceptions. The higher score indicated that shared governance is perceived as favorable administrative system by the group of participated nurses.

\section{Tool 2: Professional Nursing Autonomy Scale:}

This tool was adapted by the researcher from the instrument originally developed by (Blegen, 1993) and used by (Mrayyan, 2005) to measure nurses' autonomy over patient care and unit operations decisions on a 5-point Likert scale ranging from (1) "Nurses have no authority nor accountability" to (5) "Nurses have full independent authority and accountability". Total score of the scale ranged from (41 $205)$ with scores of (41 - 95) indicated that participated nurses perceived their professional autonomy as "low "and from (96 - 150) indicated "moderate", while from (151 - 205) indicated "high "level of autonomy.

\section{Validity of Tools}

Tools of the study were translated into Arabic by the researcher. Its content validity were revised and validated by a panel of five experts in nursing administration field including Two Assistant Professors in Nursing Administration Department - Faculty of Nursing - Minia University and Two Assistant Professors in Nursing Administration Department Faculty of Nursing - Ain-Shams University in addition to One Assistant Professor in Nursing Administration Department Faculty of Nursing - Beni-Suief University. Accordingly, wording of some items were modified.

\section{Reliability of Tools}

The reliability analysis of the study tools was done using alpha coefficient to measure the stability of its internal consistency; it was (0.72) for nurses knowledge and perceptions of shared governance questionnaire, while the test value for the autonomy scale was (0.89).

\section{Pilot Study}

A pilot study was done on $10 \%$ of participants $(8$ nurses) who were included in the study sample. They were selected randomly from the five hospitals where the study was carried out in order to check the applicability of tools, identify obstacles and problems that may be encountered during data collection and the estimate time needed to fill the questionnaires. In the light of the pilot study' findings, no major changes occurred in the tools' content or no. of items. So, tools were put in its final form.

\section{Procedure}

The study was conducted in three phases: Assessment and planning phase, implementation phase, as well as evaluation phase.

\section{i- Assessment and Planning Phase:}

This phase took up approximately nine months through which the researcher obtained the official permission from the Dean of Nursing Faculty, Minia University and from Managers of the five university hospitals where the study was carried out and approached the Jury committee for testing the content validity followed by conducting the pilot study and reliability analysis of the study tools. During this phase a 
review of the related literature covering various aspects of the study variables was done for collecting and organizing the theoretical framework of the study as well as preparing the Arabic booklet containing the scientific content of the program that was distributed to participants at the end of program implementation.

\section{ii- Program Implementation Phase:}

This phase involved obtaining an official permission from the Dean of Faculty of Medicine as the Chief Officer of Minia University Hospitals for organizing the conduction of the educational sessions of the program at Minia University Hospitals in coordination with the Chief Nursing Managers responsible for The Center of In-service Training and Continuing Education. Application of the program had taken six months at the five hospitals consequently.

\section{iii- Evaluation and follow -up Phase:}

This phase included monitoring the participated nurses' knowledge and perceptions of shared governance in addition to their level of autonomy by using the study tools. It was started jointly with the implementation phase and continued for six months later from the end of implementing the program at the last hospital setting.

\section{Ethical considerations}

- Written Approval was taken from Ethical Committee in the Faculty of Nursing - Minia University.
- $\quad$ Participation in the study was on voluntary basis and stating the possibility to withdraw at any time.

- Explaining the purpose and nature of the study was done before submitting tools of the study to the participants at each attempt of data collection for pre, post and follow-up tests and at the beginning of each educational session during the implementation phase of the program. ,

- Privacy and confidentiality of the participants' information was assured. Participants were reassured that their anonymity was maintained and the collected information wouldn't be used except for the purpose of this scientific research.

\section{Statistical design}

Data were analyzed using the statistical package for social science (SPSS) version 22. Numerical data were expressed as mean and SD. Quantitative data were expressed as percentage and percentage. For quantitative data, comparison between two variables was done using t-test, and comparison between more than two variables used ANOVA test. Chie-Square test was used for comparisons among the study variables at different periods of measurements. Relations between different numerical variables were tested using Spearman's correlation. Probability "p-value" $(<0.05)$ was considered significant and $(<0.01)$ was considered highly significant.

\section{Results}

Table (1): Percentage distribution of the participated nurses according to their socio-demographic characteristics (n=78):

\begin{tabular}{|c|c|c|c|}
\hline \multicolumn{2}{|c|}{ Socio-demographic Characteristics } & No. & $\%$ \\
\hline \multirow{3}{*}{ Age } & $25-30$ yrs. & 29 & 37.2 \\
\hline & 31-40 yrs. & 45 & 57.7 \\
\hline & $>40$ yrs. & 4 & 5.1 \\
\hline \multirow[t]{2}{*}{ Gender } & Females & 56 & 71.8 \\
\hline & Males & 22 & 28.2 \\
\hline \multirow{2}{*}{ Place of Residence } & Rural & 44 & 56.4 \\
\hline & Urban & 34 & 43.6 \\
\hline \multirow{2}{*}{ Job position } & Nurse Managers & 64 & 82.1 \\
\hline & Staff Nurses & 14 & 17.9 \\
\hline \multirow{3}{*}{$\begin{array}{l}\text { Years of } \\
\text { Experience }\end{array}$} & $\leq 10$ yrs. & 32 & 41.1 \\
\hline & 11- 20 yrs. & 43 & 55.1 \\
\hline & $>20$ yrs. & 3 & 3.8 \\
\hline \multirow{4}{*}{$\begin{array}{l}\text { Department of } \\
\text { work }\end{array}$} & General Wards (GWs) & 19 & 24.4 \\
\hline & Intensive Care Units (ICUs) & 20 & 25.6 \\
\hline & Outpatients, ER, DR \& OR. & 24 & 30.8 \\
\hline & Infection \& Quality Control Units. & 15 & 19.2 \\
\hline
\end{tabular}

Table (1) shows that (57.7\%) of the participated nurses were in the age group "31-40 yrs." . The majority of them (71.8\%) were females. More than half of participants (56.4\%) were resided in rural areas and (82.1\%) working as nurse managers. The large proportion (55.1\%) had "11-20" years of experience. About one third (30.8\%) were working in "Outpatients, ER, DR \& OR" departments.

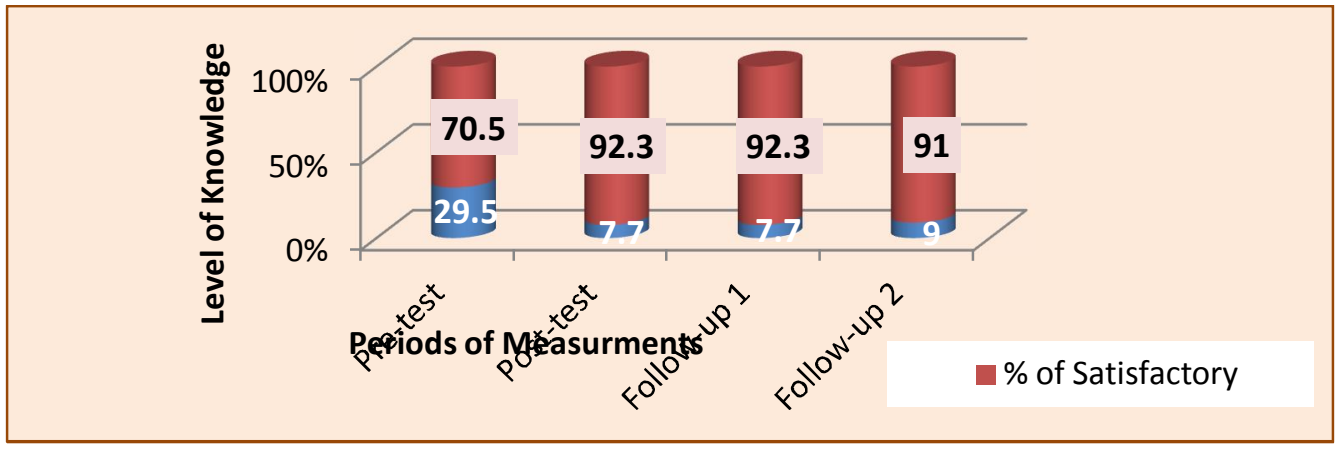

Figure (1): Percentage distribution of nurses' knowledge of shared governance level at different periods of measurements (n=78) Pre - test $=$ before implementing the educational program. Post - test $=$ immediately after program implementation. 
Follow-up 1 = after 3 months and. Follow-up 2 = after 6 months from implementing the educational program.

Figure (1) reveals that, near to one third of the participated nurses (29.5\%) had "unsatisfactory" knowledge of shared governance level and (70.5\%) of them had a "satisfactory" level of knowledge in the pre-test. While, immediately after implementing the program "post-test" and in the $1^{\text {st }}$ follow-up test there was only $(7.7 \%)$ of the participated nurses had "unsatisfactory" level of knowledge and the percentage of nurses who had a "satisfactory" level of knowledge became (92.3\%). In the $2^{\text {nd }}$ follow-up there was little change in the knowledge level among participated nurses, as there was $(91 \%)$ of them had a "satisfactory " level of knowledge and $(9.0 \%)$ had a "unsatisfactory " knowledge level.

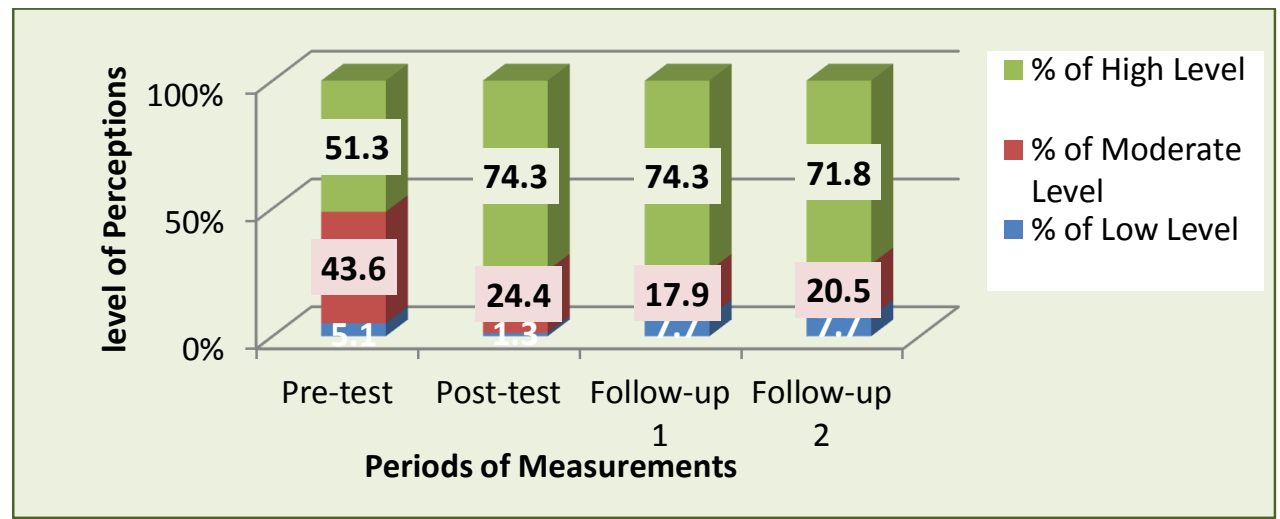

Figure (2): Percentage distribution of nurses' perceptions of shared governance level at different periods of measurements (n=78) Pre - test $=$ before implementing the educational program. $\quad$ Post - test $=$ immediately after program implementation.

Follow-up 1 = after 3 months and. Follow-up 2 = after 6 months from implementing the educational program.

Figure (2) shows that, in the pre-test there was (5.1\%) of the participated nurses had "low" level of perceptions and the percentages of nurses who had a "moderate" and "high" levels were (43.6\%) and (51.3\%) respectively. While, immediately after program implementation "post-test" the percentages of nurses who had "low", "moderate" and "high" levels were (1.3\%), (24. 3\%) and $(74.3 \%)$ respectively. In the 1 st follow-up test there was $(7.7 \%)$ of the participated nurses had "low "level of perceptions and the percentage of nurses who had "moderate" level became (17.9\%) while the percentage of nurses who had "high" level wasn't changed from that in the post-test. In the 2nd follow-up there was little change among the participated nurses as the percentages "low", "moderate" and "high" levels of perceptions were (7.7\%), (20. 5\%) and (71.8\%) respectively.

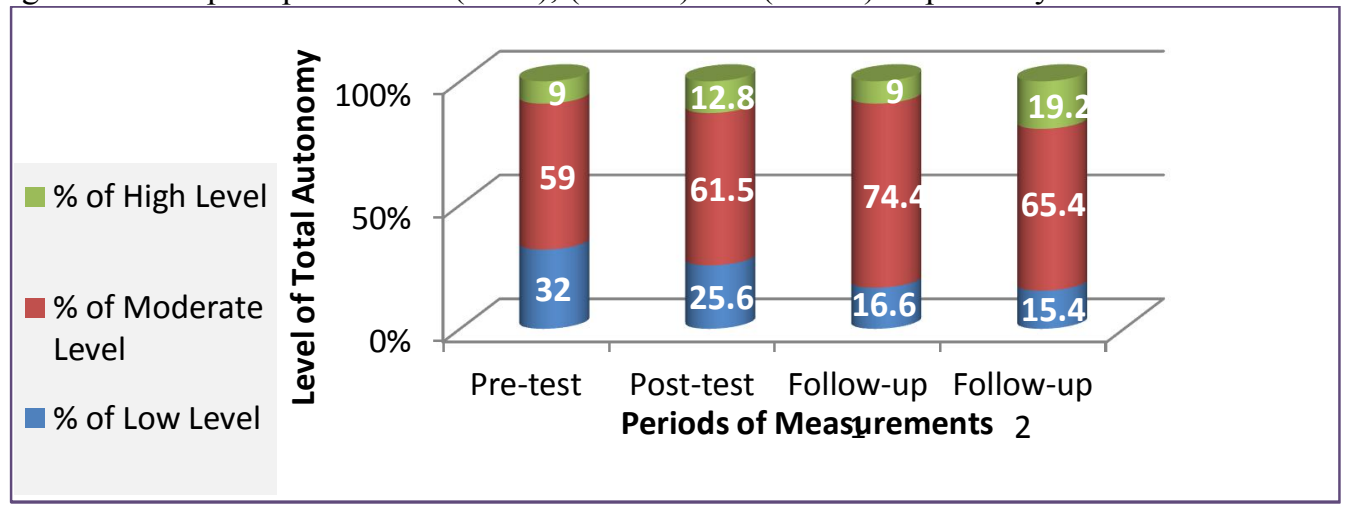

Figure (3): Percentage distribution of nurses' level of total autonomy at different periods of measurements $(\mathrm{n}=78)$

Pre - test $=$ before implementing the educational program. $\quad$ Post - test $=$ immediately after implementing the educational program. Follow-up $1=$ after 3 months and. Follow-up $2=$ after 6 months from implementing the educational program.

As evidenced by figure (3) that, the majority of the participated nurses perceived their total autonomy level as "moderate" with the following percentages $(59.0 \% ; 61.5 \% ; 74.4 \% \& 65.4 \%)$ in the pre, post, $1^{\text {st }}$ and $2^{\text {nd }}$ follow-up tests respectively. In the other hand, the percentages of "low" level were $(32.0 \% ; 25.6 \% ; 16.6 \%, \& 15.4 \%)$ respectively. While, the percentages of "high" level were $(9.0 \%)$ in both the pre and $1^{\text {st }}$ follow-up tests and were $(12.8 \%, \& 19.2 \%)$ in the post and $2^{\text {nd }}$ follow-up tests respectively.

Table (2): Comparison of total mean score in nurses' knowledge and perceptions of shared governance level at different periods of measurements $(\mathbf{n}=78)$ :

\begin{tabular}{|c|c|c|c|c|c|}
\hline \multirow[b]{2}{*}{ Testing time } & Pre-test & Post-test & Follow- up1 & Follow- up2 & \multirow{2}{*}{$\begin{array}{c}\text { P- value } \\
\text { (paired t- test) } \\
\text { df or } \\
\text { (McNemar। } \\
\text { Wilcoxon) df } \\
\end{array}$} \\
\hline & \multicolumn{4}{|c|}{ Mean + Std. Deviation } & \\
\hline $\begin{array}{l}\text { Total level of } \\
\text { Knowledge }\end{array}$ & $1.71+.459$ & $1.92+.268$ & $1.92+.268$ & $1.91+.288$ & \multirow{2}{*}{$\begin{array}{l}\mathbf{P}_{1}=0.000 * * \\
P_{2}=0.001 * * \\
P_{3}=0.010 *\end{array}$} \\
\hline p-value $\left(X^{2}\right)$ df & $0.000(13.128) 1$ & $0.000(55.846) 1$ & $0.000(55.846) 1$ & $0.000(52.513) 1$ & \\
\hline $\begin{array}{l}\text { Total level of } \\
\text { perceptions }\end{array}$ & $2.46+.596$ & $2.73+.475$ & $2.67+.617$ & $2.64+.624$ & \multirow{2}{*}{$\begin{array}{l}P_{1}=0.000 * * \\
P_{2}=0.034 * \\
P_{3}=0.567\end{array}$} \\
\hline p-value $\left(X^{2}\right)$ df & $0.000(28.615) 2$ & $0.000(65.308) 2$ & $0.000(60.308) 2$ & $0.000(53.846) 2$ & \\
\hline
\end{tabular}

Pre - test $=$ before implementing the educational program. Post - test $=$ immediately after program implementation. 
Follow-up 1 = after 3 months and Follow-up 2 = after 6 months from implementing the educational program. $\mathrm{P}_{1}=$ pre and post program implementation $\quad \mathrm{P}_{2}=$ pre and after three months of program implementation $\mathrm{P}_{3}=$ pre and after sixth months of program implementation.

It is observed from table (2) that, there was a high statistically significant difference in the total level of knowledge of shared governance among participants of the study at different periods of measurements (p-value (X2 df)=0.000 (1) with), Mean \& Std. Deviation scores of total knowledge level were $(1.71+.459 ; 1.92+.268 ; 1.92+.268 \& 1.91+.288))$ in the pre, post, 1 st $\& 2 \mathrm{nd}$ follow-up tests respectively.

This table also indicates that, there was a high statistically significant difference in the perceptions of shared governance level among participants of the study at different periods of measurements (p-value $(\mathrm{X} 2 \mathrm{df})=0.000(2)$ with Mean \& Std. Deviation scores of total level of perceptions were $(2.46+.596 ; 2.73+.475 ; 2.67+.617 ; 2.64+.624))$ in the pre, post, 1 st and 2 nd follow-up tests respectively.

Table (3): Comparison of total mean score in nurses' level of autonomy at different periods of measurements ( $\mathrm{n}=78$ ):

\begin{tabular}{|c|c|c|c|c|c|}
\hline \multirow{2}{*}{ Testing time } & Pre-test & Post-test & Follow- up1 & Follow- up2 & \multirow{2}{*}{$\begin{array}{l}\text { P-value } \\
\text { (paired t- test) df } \\
\text { or (Wilcoxon) df }\end{array}$} \\
\hline & \multicolumn{4}{|c|}{ Mean + Std. Deviation } & \\
\hline $\begin{array}{l}\text { Level of autonomy } \\
\text { over pt. care } \\
\text { decisions }\end{array}$ & $1.73+.617$ & $1.83+.653$ & $1.90+.499$ & $2.06+.610$ & \multirow[t]{2}{*}{$\begin{array}{l}\mathbf{P}_{1}=\mathbf{0 . 1 5 9} \\
\mathbf{P}_{2}=0.000^{* *} \\
\mathbf{P}_{3}=0.000^{*}\end{array}$} \\
\hline$p$-value $\left(X^{2}\right)$ df & $0.000(19.923) 2$ & $0.000(25.154) 2$ & $\begin{array}{l}0.000(60.308) 2 \\
\end{array}$ & $0.000(310.000) 2$ & \\
\hline $\begin{array}{l}\text { Level of autonomy } \\
\text { over } \\
\text { operations }\end{array}$ & $1.92+.660$ & $1.94+.651$ & $2.01+.546$ & $2.23+.623$ & \multirow{2}{*}{$\begin{array}{l}P_{1}=0.070 \\
P_{2}=0.000 * * \\
P_{3}=0.000 * *\end{array}$} \\
\hline p-value $\left(X^{2}\right) d f$ & $0.000(19.385) 2$ & $0.000(21.308) 2$ & $0.000(48.538) 2$ & $0.000(24.923) 2$ & \\
\hline $\begin{array}{l}\text { level of total } \\
\text { autonomy }\end{array}$ & $1.77+.601$ & $1.87+.611$ & $1.92+.504$ & $2.04+.591$ & \multirow{2}{*}{$\begin{array}{l}P_{1}=0.145 \\
P_{2}=0.039 * \\
P_{3}=.001 * *\end{array}$} \\
\hline p-value $\left(X^{2}\right) d f$ & $0.000(29.308) 2$ & $0.000(29.846) 2$ & $0.000(59.769) 2$ & $0.000(36.231) 2$ & \\
\hline
\end{tabular}

Pre - test $=$ before implementing the educational program. $\quad$ Post - test $=$ immediately after implementing the educational program. Follow-up 1 = after 3 months and Follow-up $2=$ after 6 months from implementing the educational program.

$\mathrm{P}_{1}=$ pre and post program implementation $\quad \mathrm{P}_{2}=$ pre and after three months of program implementation

$\mathrm{P}_{3}=$ pre and after sixth months of program implementation

As evident in table (3), there was a high statistically significant difference in the level of total autonomy as well as in the level of both autonomy over patient care decisions and over unit operations among participants of the study at different periods of measurements ( $\mathrm{p}$-value $\left(\mathrm{X}^{2} \mathrm{df}\right)=0.000$ (2) with Mean and Std. Deviation scores in the pre, post, $1^{\text {st }}$ and $2^{\text {nd }}$ follow-up tests were $(1.77$ $+.601 ; 1.87+.611 ; 1.92+.504 \& 2.04+.591) ;(1.92+.660,1.94+.651,2.01+.546 \& 2.23+.623) ;(1.73+.617,1.83+.653,1.90+$ $.499 \& 2.06+.610))$ of the three perspectives of autonomy respectively.

Table (4): Correlation matrix among level of knowledge and perceptions of shared governance and the level of autonomy at different periods of measurements $(n=78)$ :

\begin{tabular}{|c|c|c|c|c|c|c|c|}
\hline \multirow{2}{*}{$\stackrel{\Xi}{\Xi}$} & \multirow{2}{*}{\multicolumn{2}{|c|}{ Spearman's correlation }} & \multicolumn{3}{|c|}{ Subscales of autonomy } & \multirow{2}{*}{ 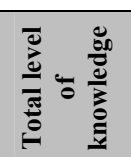 } & \multirow{2}{*}{ 曾 } \\
\hline & & & $\begin{array}{l}\text { Autonomy over pt. } \\
\text { care decisions }\end{array}$ & $\begin{array}{l}\text { Autonomy over } \\
\text { unit operations }\end{array}$ & $\begin{array}{l}\text { Level of Total } \\
\text { Autonomy }\end{array}$ & & \\
\hline \multirow{2}{*}{ 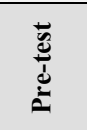 } & $\begin{array}{l}\text { Total level of } \\
\text { Knowledge }\end{array}$ & $\mathbf{r}$ (p-value) & $.310^{* *}(0.006)$ & $.014(0.903)$ & $.174(0.128)$ & 1 & "ॄ. \\
\hline & $\begin{array}{l}\text { Total level of } \\
\text { perceptions }\end{array}$ & $\mathbf{r}$ (p-value) & $.304^{* *}(0.007)$ & $.047(0.681)$ & $.166(0.148)$ & 1 & 1 \\
\hline \multirow{2}{*}{$\begin{array}{l}\overrightarrow{5} \\
\frac{0}{3} \\
\frac{1}{2} \\
0 \\
0\end{array}$} & $\begin{array}{l}\text { Total level of } \\
\text { Knowledge }\end{array}$ & $r$ (p-value) & $.013(0.909)$ & $.053(0.645)$ & $.018(0.874)$ & 1 & 1 \\
\hline & $\begin{array}{l}\text { Total level of } \\
\text { perceptions }\end{array}$ & $\mathbf{r}$ (p-value) & $.061(0.597)$ & $.105(0.360)$ & $.042(0.715)$ & $\stackrel{5}{\div}=$ & 1 \\
\hline \multirow{2}{*}{ 产 } & $\begin{array}{l}\text { Total level of } \\
\text { Knowledge }\end{array}$ & $\mathbf{r}$ (p-value) & $.067(0.559)$ & $.008(0.945)$ & $.050(0.662)$ & 1 & 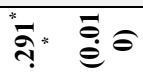 \\
\hline & $\begin{array}{l}\text { Total level of } \\
\text { perceptions }\end{array}$ & $\mathbf{r}$ (p-value) & $.071(0.536)$ & $.100(0.385)$ & $.009(0.935)$ & 1 & 1 \\
\hline \multirow{2}{*}{ 㐔 } & $\begin{array}{l}\text { Total level of } \\
\text { Knowledge }\end{array}$ & $\mathbf{r}$ (p-value) & $.327(0.095)$ & $.095(0.410)$ & $.131(0.252)$ & $i$ & $i$ \\
\hline & $\begin{array}{l}\text { Total level of } \\
\text { perceptions }\end{array}$ & $\mathbf{r}$ (p-value) & $.159(0.165)$ & $.051(0.655)$ & $.193(0.090)$ & "م: & 1 \\
\hline
\end{tabular}

Pre -test $=$ before implementing the educational program. $\quad$ Post -test $=$ immediately after program implementation.

Follow-up $1=$ after 3 months and Follow-up $2=$ after 6 months from implementing the educational program.

$* *$ Correlation is significant at the $(\mathrm{p}<0.05)$ and is highly significant at the $(\mathrm{p}<0.01)$ level.

Table (4) shows that, there was statistically significant fair positive correlation between the level of knowledge and perceptions of shared governance before implementing the educational program (pre-test) and at the two follow-up test measures(after $3 \& 6$ months from implementing the educational program) with a score of (r (p-value) $=.404(0.000) ; .291(0.010) \& .379(0.001)$ respectively. This table shows also that, there was statistically significant fair positive correlation between both of knowledge and perceptions of shared governance level and the level of autonomy over patient care decisions at the time measure before 
implementing the educational program (pre-test) with a score of (r (p-value)=.310 (0.006) \& .304 (0 .007)) respectively. However, there was no statistical significant correlation found between either the knowledge or perceptions of shared governance level and both the level of total autonomy and the level of perceived autonomy over unit operations at all-time measures before and after implementing the educational program (pre, post, $1^{\text {st }} \& 2^{\text {nd }}$ follow-up tests)

\section{Discussion}

Education on shared governance principles, concepts, competencies, roles, council structure, and processes were vital to the implementation and integration of shared governance and set the pace for its success (Shepherd et al., 2014). On the other side, autonomy is a critical aspect of professional practice and never more so than when considering professional nurses who embrace an entire range of tasks, skills, and practices within their profession (Bassett \& Miller, 2017).

The study sample consisted of (78) professional nurses; the large proportion of them were within the age group" 31- 40 yrs.". Regarding their gender, the majority were females, while males constituted about a quarter of the total sample. According to the place of residence, more than half of the participated nurses reside in "Rural" areas. According to the current job position, the majority of the participated nurses were working as nurse managers while, near to a quarter of them were direct care nurses "Staff nurses". In relation to the years of experience, more than half of the study sample had "11-20 yrs. " of experience. For work department, about one third of the participated nurses were working in "Outpatient clinics, ER, DR \& OR departments".

The findings of the present study revealed a high statistically significant improvement in the level of nurses' knowledge and perceptions of shared governance at all test measures that followed implementing the educational program (post, $1^{\text {st }} \& 2^{\text {nd }}$ follow-up tests) than that of before program implementation (pre-test). This result reflects the implications of successfulness of shared governance educational program.in achieving a high level of professional autonomy among nursing staff as evident from the positive change that was found between pre-test / post-test measures.

This result, reported by the present study, was in harmony with results of the study conducted by (Rundquist, 2014) which demonstrated a statistically significant change in the participants' knowledge and perceptions from pre-test to post-test. This result was also in line with (Glasscock, 2012) who revealed that, the mean overall governance score in his study increased at post-implementation of a governance structure than pre-implementation.

The result of the present study indicated that there were significant differences in overall level of nurses' knowledge and perceptions of shared governance between the pretest and the three measuring times after the program implementation. This was though by the increase of total mean score of knowledge and perceptions level immediately after program implementation than the level that was before implementing the educational program. However, the level of nurses' knowledge and perceptions slightly decreased after three and sixth months later from implementing the program with statistically significant difference.

From researcher point of view, the changes in professional nurses' knowledge and perceptions of shared governance after implementing the training program might be attributed to the refreshment and broadening of their knowledge base as a result of what they learned and gained of knowledge about the concept of shared governance as a new approach of administrative structure through the new concepts and principles added and clarified within the different sessions of the educational program

In addition, the clarification and distinguishing of the different concepts such decisional involvement, participation, participatory management, shared leadership and team work which commonly confused in meaning with the concept of shared governance may also considered as a contributing factor to the increased knowledge and perceptions levels. While, the slight decrease in knowledge and perceptions of shared governance noted in the two follow-up attempts could be attributed to what was forgotten from essential information that hoped to be compensated by the given Arabic booklet as a handouts about the program contents.

Regarding findings of the current study concerning the level of autonomy, it was noted that the majority of the participated nurses had a "moderate" level of professional autonomy either in regard to their perceived autonomy over patient care decisions and over unit operations or their total autonomy. It was noted also that, there was an increase in the level of autonomy perceived by the participated nurses during the three time measures after implementing the educational program (post, $1^{\text {st }} \& 2^{\text {nd }}$ follow-up tests) than what was in the time measures before program implementation (pre-test).

This result was supported by (EL Housary, 2017) whose results concluded that, about half of nurses reported moderate level of job autonomy. As well, this result was in accordance with the study conducted by (Elksas, 2017) which revealed that, more than half of staff nurses had average level of professional nursing autonomy. Additionally, this result was supported by (Al-Faouri et al., 2014) who concluded that registered nurses working in a Jordanian University Hospital perceive good control over their professional practice. This result was also supported by (Disher, 2012) whose results indicated that, the nurses had an average amount of access to autonomous self-governance.

Furthermore, this result was in accordance with results of (Iliopoulou \& While, 2010) which indicated that, overall respondents reported acting with moderate autonomy. In addition, this result was also supported by Mrayyan (2005) who concluded that nurses total work autonomy was moderate and they were more autonomous about decisions relating to patient care than unit operations. In contrast, this result of the present study was differed from (Gilman, 2018) as the advanced practice nurses participated in his study had a high level of perceived autonomy.

Finally, Results of the current study showed that, there was statistically significant fair positive correlation between nurses' level of knowledge and perceptions of shared governance at the time measure before implementing the educational program and at the two follow-up test measures, while, also a statistically significant fair positive correlation found between each the level of nurses' knowledge and perceptions of shared governance and their level of perceived autonomy over patient care decisions only at the time measure before implementing the educational program. However, there was no statistical significant correlation found between either the level of knowledge or perceptions of shared governance and both the level of perceived autonomy over unit operations 
or the level of total autonomy at different periods of measurements.

From the researcher' point of view, the insignificant relation among the levels of knowledge or perceptions of shared governance and autonomy at any of the testing measures following program implementation might be as a result of clarity achieved by the new concepts and principles discussed within the different educational sessions of the program about areas of nursing responsibilities over which professional nurses should have some degree of authority, autonomy or control compared to what is actually done of restrictions in professional nursing autonomy either by organizational constraints, legal/professional practice parameters, work overloads or absence of specified job descriptions of nursing categories.

With taking into consideration that the current study was the first one that monitored the level of professional nursing autonomy before and after implementing an educational program about shared governance, it was difficult to clarified its results in this two regard (the increased level of autonomy perceived by the participated nurses after the program implementation and the presence or absence of a significant correlation among the study variables either before or after implementing the educational program) in the light of results of any other previous studies.

\section{Conclusion}

- The provided educational program contributed to the presence of a positive change in nurses' knowledge and perceptions of shared governance as well as in the level of perceived professional autonomy with statistically significant differences between pre and the three of posttest measures.

- There was statistically significant fair positive correlation between both of knowledge and perceptions of shared governance, in addition to a statistically significant fair positive correlation between each of knowledge and perceptions of shared governance and autonomy over patient care decisions before implementing the educational program. However, there was no statistical significant correlation found between either the knowledge or perceptions of shared governance and both of total autonomy and autonomy over unit operations at all-time measures before and after program implementation.

\section{Recommendations}

Based on the findings of the current study the following recommendations suggested:

- This management development educational program should be periodically conducted for all nursing categories.

- Integrate the philosophy of shared governance into the values and mission of the organization through developing a set of policies that related to the principles and methods of its application.

- Allow nursing staff to be involved in the major organizational decisions and committees such as: quality, infection control, environment, and training committees in order to strengthen and promote professional nursing autonomy.

\section{References}

1) Abdelkader, R., Al-Hussami, M. O., , Al barmawi, M., Saleh, A., and Shath, A. Th. (2012): Perception of academic nursing staff toward shared Governance. Journal of Nursing Education and Practice, August 2012,Vol.2,No.3;DOI:10.5430/jnep.v2n3. ISSN 19 $46 \quad 25-4040 \quad$ E-ISSN $1925-4059$ http://dx.doi.org/10.5430/jnep.v2n3.

2) Abood, S. A. and Thabet, M. (2018): Shared Governance as perceived by Nurses' Manager and its Relation to Work Engagement. IOSR Journal of Nursing and Health Science (IOSR-JNHS) e- ISSN: 2320-1959.p- ISSN: 2320-1940 Volume 7, Issue 2 Ver. IX (Mar-Apr .2018), PP 61-70 www.iosrjournals.org.

3) Al-Faouri, I.G., Ali, N.A., and Essa, M.B. (2014): Perception of shared governance among registered nurses in a Jordanian university hospital. International Journal of Humanities and Social Sciences, 4(6), 254-262. Retrieved from www.ijhssnet.com

4) Barden A.M., Griffin M.T.Q., Donahue M., Fitzpatrick J. J. (2012) Shared governance and empowerment in registered nurses working in a Hospital Setting. Nursing Administration Quarterly, 35(3), 212-218.

5) Bassett, S. E. and Miller A. (2017): Nurses' perceptions of occupational self-efficacy/workplace autonomy related to organizational/structural empowerment. Doctorate Dissertation, Capella University. Retrieved from ProQuest database, LLC UMI 10260481.

6) Blegen, M. A., Goode, C., Johnson, M., Maas, M., Chen, L., andMoorhead, S. (1993): Preferences for decision-making autonomy. Image: Journal of Nursing Scholarship, 25(4), 339-344.

7) Charland, J. B. (2015): "Organizational Context, Shared Governance Structure and Outcomes in Veteran Affairs Hospitals". Open Access Dissertations. $\quad$ Paper 344. http://digitalcommons.uri.edu/oa_diss/344.

8) Disher, C. E.(2012): registered nurses' access to autonomous self-governance structures and retention in long-term care. Doctor of health administration dissertation, University of Phoenix. Retrived from ProQuest database, UMI Number: 3570372.

9) EL Housary, N.M. A. (2017): Unit Nurse Managers' Role for Empowering Staff Nurses Job Autonomy. Master thesis, Faculty of Nursing, Tanta University, Egypt. Available at ww. eulc.edu.eg/eulc_v5/Libraries/Thesis/BrowseThesisP ages.aspx.

10) Elksas, E. Is. Ib. (2017): Professional Nursing Autonomy and Organizational Support: Staff Nurses' Perspective. Master thesis, Faculty of Nursing, Alexandria University, Egypt. Available at www. eulc.edu.eg/eulc_v5/Libraries/Thesis/BrowseThesisP ages.aspx.

11) Gilman P. R. (2018): Relationships between APRN state practice authority, perceived autonomy, professionalism, and inter-professional team function among a national sample of APRNS in the U.S. A doctor of pphilosophy in Nursing dissertation, The University of New Mexico Albuquerque, New 
Mexico. Retrieved from Pro-Quest 10977879.

12) Glasscock, Sh., (2012): "Implementation of Shared Governance". Graduate Theses, Dissertations, and Capstones. Paper 7. Available at jstemmer@bellarmine.edu.

13) Hess, R.G. and Swihart, D. (2013): Shared governance: What it can mean for nurses. Nursing Spectrum ;25(1):38-43. Nurse.com. Retrieved from $\mathrm{http} / / /$ ce.nurse.com/ce635/shared-governance/.

14) Iliopoulou K.K. and While A.E. (2010): Professional autonomy and job satisfaction: survey of critical care nurses in mainland Greece. Journal of Advanced Nursing 66(11), 2520-2531. doi: 10.1111/j.13652648.2010.05424.

15) Mrayyan, M.T. (2005): American nurses' work autonomy on patient care and unit operations. British Journal of Nursing, 14(18), 962-967.

16) Rundquist, J. M. (2014): Nursing Managers' Perceptions, Knowledge and Commitment to Shared Governance. All Regis University Theses. Paper 181.

17) Santos, J.L.G., Erdmann, A.L., Andrade, S. R., Mello,A. L. S. F., Lima, S. B. S., Pestana, A. L. (2013): Nursing governance: an integrative review of the literature. Rev Esc Enferm USP; 47(6):1414-25.

18) Shepherd L.M., Harris M.L., Chung, H, and Himes, E.M. (2014): Using the Awareness, Desire, Knowledge, Ability, Reinforcement Model to build a shared governance culture. Journal of Nursing Education and Practice, Vol. 4, No. 6 ISSN 19 